Egypt. Acad. J. Biolog. Sci., 13(3):127-135 (2020)

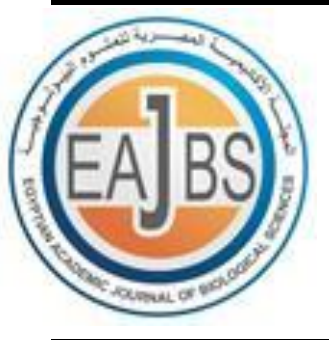

Egyptian Academic Journal of Biological Sciences

ISSN 1687- 8809

http://eajbsa.journals.ekb.eg/

\title{
Benthic Cyanobacterial Flora and PCR Based Assessment of Toxin Production of Kalenjir Region in Shastfich River of Baft, Iran
}

\author{
Hassan Salari", Hossein Mozafari, and Mohsen Salajegheh \\ Department of Ecology, Institute of High Technology and Environmental Sciences, Graduate \\ University of Advanced Technology, Kerman-Iran \\ Email: $\underline{\text { h_salari57@yahoo.com }}$
}

\begin{abstract}
ARTICLE INFO Article History

Received:19/5/2020

Accepted:20/8/2020

Keywords:

Cyanobacterial

flora, Kerman,

PCR, toxic

cyanobacteria
\end{abstract}

\section{ABSTRACT}

Cyanobacteria as the first photosynthetic organisms of planet earth are made it habitable for its residents. They are able to tolerate extreme environmental conditions. Secondary metabolites of cyanobacteria are key factors that make them able to survive in such environments. Some of these secondary metabolites are considered and under investigation for utilizing in biotechnology. Cyanotoxins are among cyanobacterial secondary metabolites which are detrimental and, in some cases, vital for the life of human and animals and according to international standards they should not pass more than a limited defined amount. Thus, no research has done about cyanobacterial toxins in the Shastfich river of Baft city of Kerman province of Iran before and this research is the first attempt to find cyanobacterial toxins by PCR approach for this site. In the present study, we investigated the cyanobacterial flora of Kalenjir region in Shastfich river of Baft. Iran. After sampling and treating them by BG11 medium they identified microscopically using valid international keys. Two genera identified as potentially toxic so in order to identify toxic strains, PCR based microcystin detection has carried out which lead to no band on an electrophoresis agarose gel. The strains of toxic and non-toxic cyanobacteria can be present in one place and compete ecologically and each of them survives and be dominant by the aid of their favorite environmental factor. To conclude, it is suggested to examine the presence of nodularin and cylindrospermopsin gene clusters in cyanobacteria of this region and measurement the amounts of mentioned toxins in water throughout a year.

\section{INTRODUCTION}

Cyanobacteria are the first photosynthetic organisms of the planet earth. They made the earth livable for its inhabitants by producing oxygen during Precambrian era (Schirrmeister et al., 2016). These microscopic organisms still show the capability of tolerating extreme environmental conditions and live in harsh conditions like salty, acidic, super-hot environments (Seckbach, 2007). One of the key factors that make cyanobacteria 
survive in such extreme conditions is the production of secondary metabolites by them (Vijayakumar \& Raja, 2018). These features of cyanobacteria have caught scientist's attention for using them in biotechnology and for the production of drugs and cosmetics (Abed et al., 2009).

Among cyanobacterial secondary metabolites, cyanotoxins are detrimental and even vital for the health of humans, pets, and wild animals. The reports of water contamination by these toxins and therefore death of pets published in many years (Krienitz et al., 2003). Cyanotoxins can affect the nervous system (neurotoxins), liver (hepatotoxins), and skin (dermatoxins). Microcystins that have a cyclic peptide chemical structure are one of cyanobacterial hepatotoxins and in some doses can cause cells of the liver to degradation and necrosis in addition to dramatic changes in liver enzymes and chemistry (Mrdjen et al., 2018). And functionally they inhibit serine/threonine-protein phosphatase 1 (PP1) enzyme (Moore et al., 2016). According to the standard of world health organization, the maximum allowed existence of microcystin in water is $1 \mu \mathrm{g} / \mathrm{L}$ (Bartram \& Chorus, 1999). The cyanobacterial toxins are produced by a non-ribosomal pathway in cells (Kurmayer \& Christiansen, 2009). In order to detect toxic strains, microscopic and even molecular taxonomy using $16 \mathrm{~s}$ rRNA proved to be useless. However, investigation of gene clusters involving in toxin production can be an indicator (El Semary, 2010).

Several researchers have undertaken research about the presence of toxic cyanobacterial species in water resources. Molecular studies have also done by domestic and international scholars to check the presence of toxic species based on PCR method. Dos Anjos et al. (2006) worked on the occurrence of toxic blooms in reservoirs Sao Paulo city, Brazil. The first combination confirmed the presence of toxic species by amplification of the microcystin synthetase- $m c y B$ gene by performing PCR and measured the amount of toxin using mass spectrometry. Gkelis and Zaoutsos (2014) examined the potential threat of cyanobacterial blooms in Greece by assessing their abundance in addition to measuring toxin existence by ELISA method. Weller (2011) investigated the distribution of cyanobacteria in three lakes in New Zealand. He reported Microcystis spp., Anabaenaspp., Coelosphaeriumspp. and Aphanocapsaspp. from there and 11 out of 18 collected samples showed positive results for the existence of $m c y E$ gene. Mehrabiani et al. (2016) worked on cyanobacteria of Amirkelaye lagoon and examined the occurrence of toxic species by PCR method. They reported the presence of cyanobacteria that can be producing microcystin in the studied lagoon. However, no research has done about cyanobacterial toxins in the Shastfich river of Baft city of Kerman province of Iran before and this research is the first attempt to find cyanobacterial toxins by PCR approach for this site. For this aim of this study, we investigated the cyanobacterial flora of Kalenjir region in Shastfich river of Baft. Iran.

\section{MATERIALS AND METHODS}

Samples station selected from phytobenthic and periphyton of Kalenjir freshwater of Shastfich river with coordination of $291053.4 \mathrm{~N}$ and 5651 01.4E (Fig. 1). Soils and sediments of the bottom to the depths of 10 centimeters were collected. For periphyton samples things like rocks and stems and leaves of trees and pieces of woods that cyanobacterial samples attached to them were taken and kept in glass bottles and filled with some of the site water (97). Samples were cultured using modified BG11 medium under the culture condition of $280-300$ photon $\mathrm{mol} \mathrm{s}^{-1} \mathrm{~m}^{-2}$ and 28 degrees centigrade and then for purification of samples they were sub-cultured several times.

Morphological identification of samples was done using a light microscope of Olympus BH-2 and fluorescent microscope Olympus Vanox $\mathrm{AH} 2$ and by comparing the 
traits of the colony, filament, vegetative, heterocyst and akinete cells using valid international keys of Prescott (Prescott, 1982), Desikachary (Desikachary, 1959) and john (York \& Johnson, 2002).

For DNA extraction, after growing samples in liquid culture, $15-20 \mathrm{ml}$ of broth medium was taken. Then the samples centrifuged at $1500 \mathrm{~g}$ for 5 minutes at $4 \mathrm{C}$. The supernatant aqueous phase was removed and the pellet transferred to 2 milliliters microcentrifuge tube.
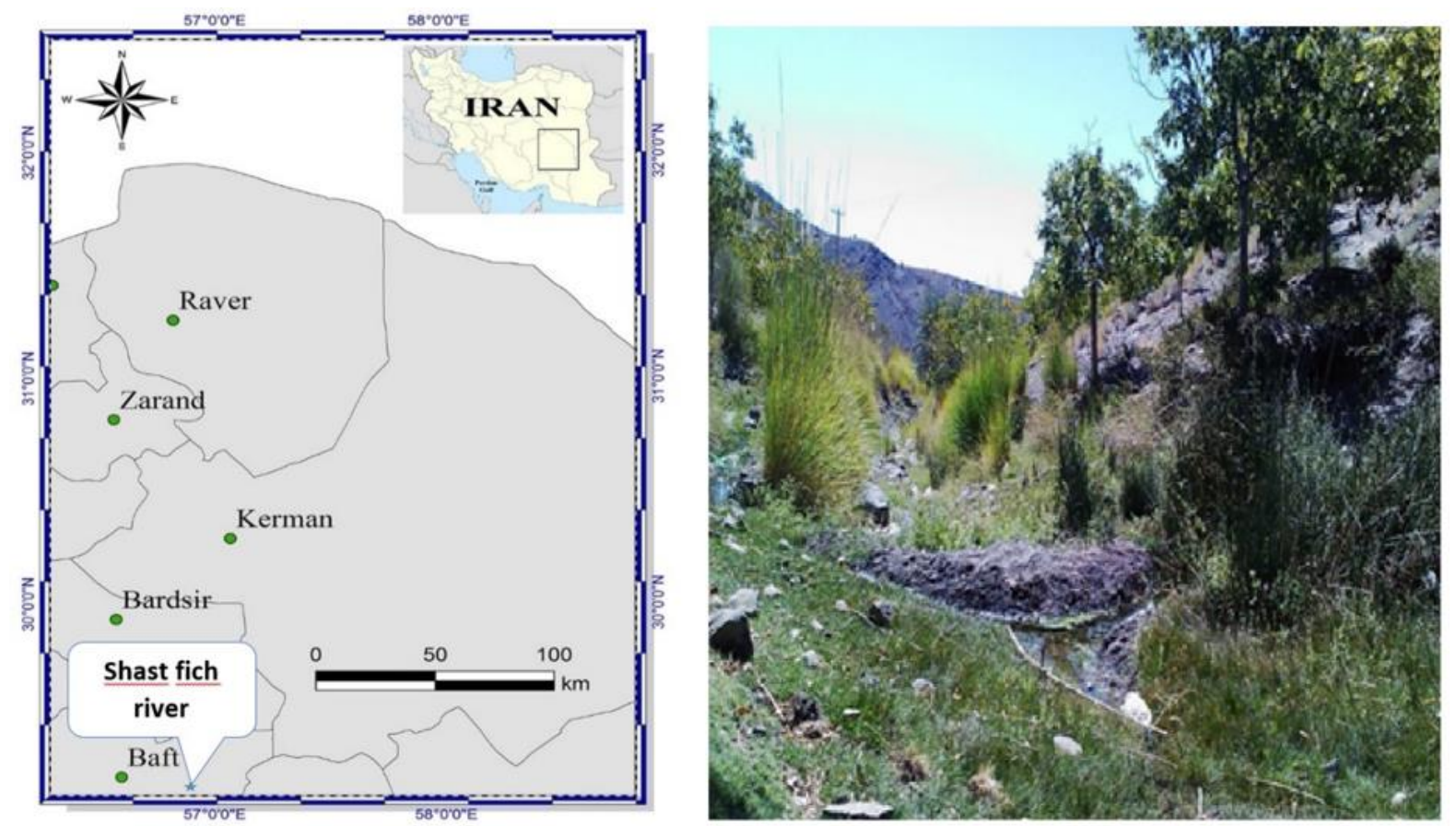

Fig. 1. Map showing the exact coordination of studies area (Left) and the photograph of the sampling site (Right).

Samples grinded with liquid nitrogen to a very fine powder in 2 milliliters microcentrifuge tube. Then the samples were mixed with $600 \mu 1$ Lysis buffer and vortexed for 30 seconds. Then they incubated at 55 degrees centigrade for 1 hour in a water bath, the microtubes were inverted every 15 minutes for the solution of the crushed tissue with buffer. Then the samples centrifuged at $12000 \mathrm{rpm}$ for 2 minutes at 4 degrees centigrade. The upper phase was transferred into a new 1.5-milliliter microtube (almost 550-600 $\mu \mathrm{l}$ ). An equal volume of cold chloroform was added then vortexed for 15 seconds and centrifuged at 12000 rpm for 2 minutes at 4 degrees centigrade.

The upper phase was separated and then transferred into a new 1.5-milliliter microtube. $1000 \mu \mathrm{l}$ of cold precipitation buffer was added at -20 degrees centigrade. The tubes were decanted by inverting gently and placed at -20 degrees centigrade for 30 minutes. Samples centrifuged at $12000 \mathrm{rpm}$ for 10 minutes at 4 degrees centigrade. The upper aqueous phase was removed. $200 \mu \mathrm{l}$ of wash buffer was added. Then they decanted again by inverting gently and centrifuged at $12000 \mathrm{rpm}$ for 10 minutes at 4 degrees centigrade. The supernatant decanted and the microtube placed in a tissue paper. The pellet of DNA dried at 37 degrees centigrade for 20 minutes. The DNA was dissolved in $30-50 \mu 1$ of distilled water and stored at 4 degrees centigrade for a short time.

The PCR process was done using IGF-352 microcystin gene PCR detection kit from Iranian gene Fanavar Company according to the manufacturer's method. In brief, by adding $20 \mu 1$ of 1x PCR MIX (containing mcyA gene), Taq-DNA polymerase and mixed them thoroughly by shaking and spinning. Then $20-25 \mu \mathrm{l}$ of mineral oil and $5 \mu \mathrm{l}$ of DNA were 
added. The mixture samples vortexes for 3-5 seconds. The thermal cycler program was as follows: $94 \mathrm{C}$ for 5 minutes. The following program repeated for 35 cycles $(94$ degrees centigrade for 1 minute, 56 degrees centigrade - 40seconds, 72 degrees centigrade for 1 minute). Finally samples centigrade for 7 minutes at 72 degrees. And then $10 \mu \mathrm{l}$ of amplificated samples were directly loaded in a 2 percent agarose gel.

\section{RESULTS}

Ten of the identified cyanobacterial species are presented in Figure 2. These species belong to two orders of Nostocales, Chroococcales and four families of Nostocacea, Chroococcaceae, Microcystaceae, and Scytonemataceae. Among these species, Nostoc with 5 species is the dominant one and the family of Nostocacea is the dominant family.

We examined a part of the microcystin synthetase gene, mcyA and the results have shown no band on agarose gel electrophoresis. Most of the researchers who worked toxicity of on benthic cyanobacteria reported microcystins, nodularins and cylindrospermopsins which are hepatotoxic and saxitoxins, anatoxin-a and homoanatoxin-a which are neurotoxic (Gugger et al., 2005; Izaguirre et al., 2007; Seifert et al., 2007; Smith et al., 2011). So, those benthic cyanobacteria which are hepatotoxic are microcystin, nodularin, and cylindrospermopsin. However, researchers mostly focused on the examination of microcystin in the past researches and the cause can be the available routine tests for microcystin and the fact that many studies proved that benthic species found that produce microcystin and not all of the toxins are commonly examined by scholars (Catherine et al., 2013). For example, benthic cyanobacterium Lyngbya wollei proved to produce saxitoxins and cylindrospermopsin toxins(Carmichael et al., 1997; Seifert et al., 2007). 

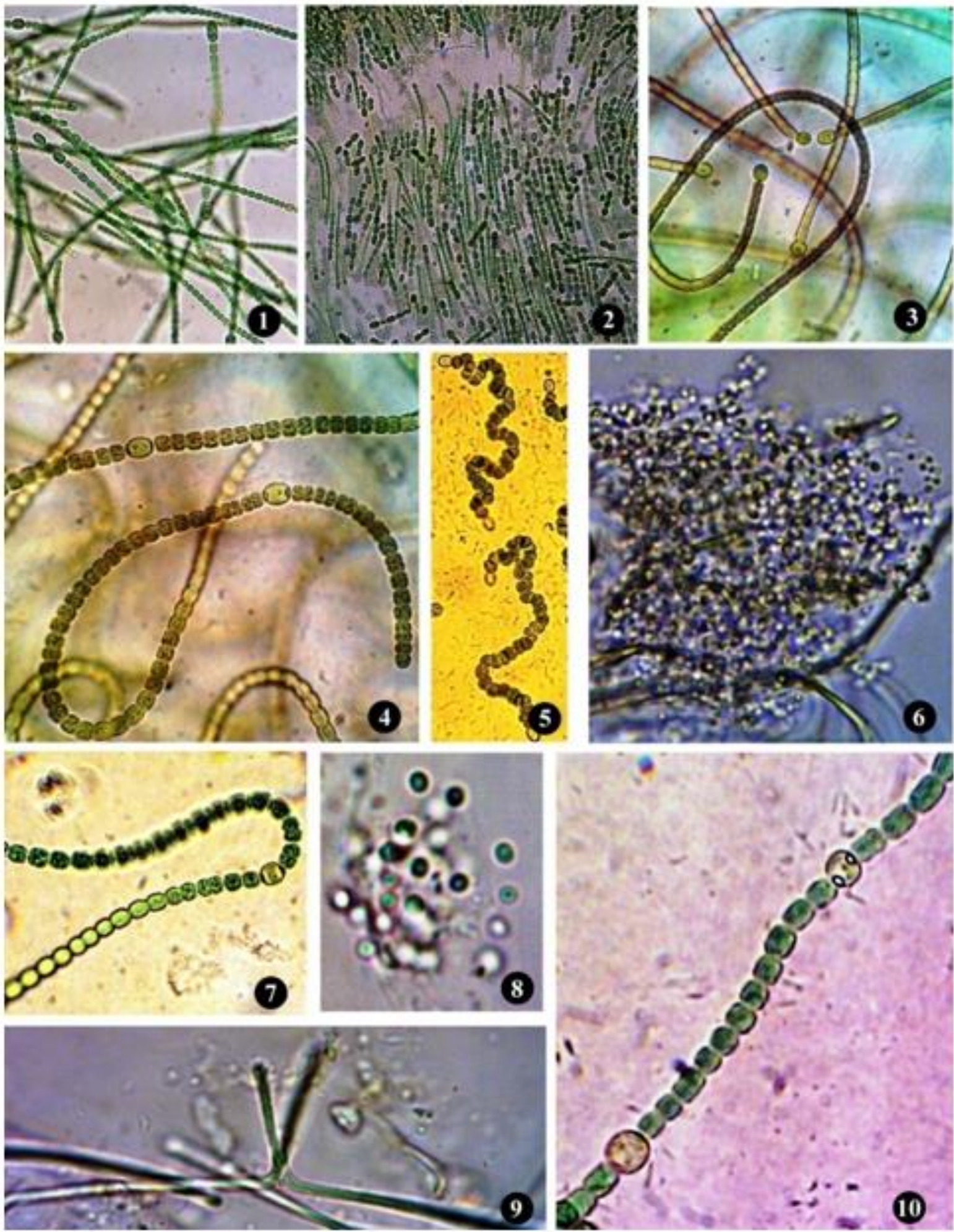

Fig. 2, representing ten of the identified cyanobacterial species in the studied region. 1, Anabaena Variabilis; 2, Anabaena wisconsinense; 3, Nostoc spongiaforme; 3, Nostoc commune; 5, Nostoc microscopicum; 6, Microcystis aeruginosa; 7, Nostoc linckia; 8, Chroococcus disperses; 9, Scytonema sp.; 10, Nostoc puctiforme. Magnification of 7,5,2,1 (x400) and 10,9,8,6,4,3 (x1000). 


\section{DISCUSSION}

The various existence species of cyanobacterial in an ecosystem can show the ecological status of that region. For example, colony-forming species like Anabaena and Microcystis in lakes and water resources represent mesotrophic (the moderate biological production) to Eutrophic status (high biological production) and presence of unicellular species like Synechococcus shows oligotrophic status (low nutrition) in the water ecosystem (Wehr, 2011).

In a research M.Skulberg et al. (1993) studies more than 40 species of Nostoc genius and four of them, species of Nostoc linkia, Nostoc paludosum, Nostoc rivulare and Nostoc zetteresteditii recognized as toxic strains. Raziuddin et al. (1983) investigated the toxic effects of the unicellular cyanobacterium Microcystis aeruginosa, and first proved the production of both neurotoxins and hepatotoxins by it. Therefore, both microscopically identified species of Nostoc linkia and Microcystis aeruginosa which are present in the studies region of Kalenjir region of Shastfich River are considered to be potentially toxic. In addition, the residents of the studies region reported several deaths of pets and wild animals around the region due to a liver disorder. Hence, these two potentially toxic cyanobacterial trains can be the cause of their death.

Basically, the cause of toxic products in both benthic and planktonic cyanobacteria is still unknown. Toxic and non-toxic strains of benthic cyanobacteria from one species can exist in one place and their toxin production can be regulated and also one can be dominant over the other by some environmental factors. Wood et al. (2010) sampled seven rivers in New Zealand and checked variations of homo/anatoxin-a. Their work showed that of seven sampled sites, only one contained some amounts of homo/anatoxin-a and in three sites both toxic and non-toxic strains co-occurred.

Temperature also can be a key environmental factor in toxin production. Heath et al. (2011) suggested the toxic strain of Phormidium can be defeated in the contest by non-toxic strains by water temperature variations. They observed homo/anatoxin-a only exists in months of the year when the temperature of the water is more than 13.4 degrees centigrade.

Environmental factors like deficiency or excess of nutrients can affect toxin production in cyanobacteria. For example, by limiting nitrogen, the production of microcystin increases through enhancement of transcription of $m c y$. And UBA radiation can helps the growth of microcystin producing cyanobacteria (Boopathi \& Ki, 2014).

The climatic conditions of the region are important in the timing and duration of the bloom season of cyanobacteria. Mass occurrences of cyanobacteria are most prominent during the summer and early autumn and may last 2-4 months in temperate zones. In Mediterranean regions or subtropical climates, the bloom season may start earlier and persist longer.

High range concentrations following treatment of a large bloom with algicide, which released microcystins in France, four months is not uncommon, and in Japan, Portugal, Spain, South Africa and southern Australia blooms may occur for up to six months or longer. Cyanobacterial blooms may occur almost all year round in dry years, in tropical or subtropical such as China, Brazil, and Australia. In shallow lakes, populations of Planktothrix agardhii (Oscillatoria agardhii) may overcome perennially for many years. In deeper stratified reservoirs and lakes with reasonable nutrient pollution, Planktothrix rubescens (Oscillatoria rubescens) may shape blooms at the border between the warmer upper and colder deeper layers of water during summer, but keep high, evenly distributed density throughout the entire water body during winter. Both Planktothrix species may have high amounts of microcystins. In winter, Blooms of cyanobacteria, especially Planktothrix agardhii, have been found under the ice in German and Scandinavian lakes and can thus be 
an all year-round problem.

Though toxic cyanobacteria occur in a great number of lakes, reservoirs, and rivers in the world, reports on the seasonal change of cyanobacterial species composition and toxin concentration are infrequent. There is a limited number of studies on spatial, seasonal, and day to night variations in lakes. A high degree of spatial variation of bloom toxicity was due mostly to variations in the relative amounts of toxic Microcystis aeruginosa throughout the lake, rather than to substantial variations in cell toxin content (Carmichael and Gorham (1981)). Similar trends were observed for other measurements of toxin concentrations in lakes; samples taken at the same time from dissimilar areas of the lake may show wide divergence in cyanotoxin content (Ekman-Ekebom et al., 1992; Kotak et al., 1995; Vezie et al., 1998). A study in Alberta, Canada and revealed significant variation in toxin concentrations among the three lakes studied, both within and between years, even though the lakes were situated within the same climatic region (Kotak et al., 1995). In any season, individual water bodies have their own populations of cyanobacteria and algae, the dominance of which is determined by the weather and the specific geochemical conditions of the lake. If there are no main changes in these circumstances, toxic blooms are likely to recur annually in those lakes that have a history of toxic blooms (Wicks and Thiel, 1990; EkmanEkebom et al., 1992). Certain species, including the highly toxic P. Rubescens and Planktothrix agardhii, are known to produce maximum mass occurrences deep in the water column and which may be overlooked by surface monitoring of waters. Such situations may also cause difficulties for water treatment (Lindholm and Meriluoto, 1991).

According to the above-stated pieces of evidence and reports from residents of studies region in terms of the death of pets and wild animals by liver disorder, it is probable that those happened by the existence of nodularin or cylindrospermopsin cyanobacterial toxins. Furthermore, the production of toxins and existence of toxin-producing strains in competition with non-toxic strains might be varied during seasons of the year with different temperatures and environmental conditions. So, it is suggested to investigate the existence of two genotypes of nodular in and cylindrospermopsin by molecular approach. Moreover, plan to detect and trace the amount and existence of toxic strains and comparing them in different months of the year.

\section{Acknowledgments}

The financial cost of this research was funded by the Institute of High Technology and Environmental Sciences, Kerman-Iran. This article is the result of a research project No. 96/1526 conducted at the mentioned institute.

\section{REFERENCES}

Abed, R. M., Dobretsov, S. Sudesh, K. (2009). Applications of cyanobacteria in biotechnology. Journal of Applied Microbiology. 106(1), 1-12.

Bartram, J., Chorus, I. (1999). Toxic cyanobacteria in water: a guide to their public health consequences, monitoring and management: CRC Press.

Boopathi, T., Ki, J., S. (2014). Impact of environmental factors on the regulation of cyanotoxin production. Toxins, 6(7), 1951-1978.

Carmichael, W.W. (1992). A Status Report on Planktonic Cyanobacteria (Blue Green Algae) and their Toxins. EPA/600/R-92/079, Environmental Monitoring Systems Laboratory, Office of Research and Development, US Environmental Protection Agency, Cincinnati, Ohio.

Carmichael, W., Evans, W., R Yin, Q., Bell, P., Moczydlowski, E. (1997). Evidence for paralytic shellfish poisons in the freshwater cyanobacterium Lyngbya wollei (Farlow ex Gomont). Applied Environmental Microbiology. 63(8): 3104-3110. 
Catherine, Q., Susanna, W., Isidora, E.-S., Mark, H., Aurelie, V., Jean-François, H. (2013). A review of current knowledge on toxic benthic freshwater cyanobacteria-ecology, toxin production and risk management. Water Research, 47(15), 5464-5479.

Desikachary, T. V. (1959). Cyanophyta (Vol. 2): Indian Council of Agricultural Research New Delhi.

Dos Anjos, F. M., do Carmo Bittencourt-Oliveira, M., Zajac, M. P., Hiller, S., Christian, B., Erler, K., Pinto, E. J. T. (2006). Detection of harmful cyanobacteria and their toxins by both PCR amplification and LC-MS during a bloom event. Toxicon, 48(3), 239245.

Ekman-Ekebom, M., Kauppi, M., Sivonen, K., Niemi, M. and Lepistö, L. (1992). Toxic cyanobacteria in some Finnish lakes. Environmental Toxicology and Water Quality, 7: 201-213.

El Semary, N. (2010). Modern methods for detection and elimination of microcystins toxins produced by cyanobacteria: mini-review. Journal of Applied Sciences, 10(15), 16621666.

Gkelis, S., Zaoutsos, N. (2014). Cyanotoxin occurrence and potentially toxin producing cyanobacteria in freshwaters of Greece: A multi-disciplinary approach. Toxicon, 78, $1-9$.

Gugger, M., Lenoir, S., Berger, C., Ledreux, A., Druart, J.-C., Humbert, J.-F., Bernard, C. J. T. (2005). First report in a river in France of the benthic cyanobacterium Phormidium favosum producing anatoxin-a associated with dog neurotoxicosis. Toxicon, 45(7), 919-928.

Heath, M. W., Wood, S. A., Ryan, K. (2011). Spatial and temporal variability in Phormidium mats and associated anatoxin-a and homoanatoxin-a in two New Zealand rivers. Aquatic Microbial Ecology, 64(1): 69-79.

Lindholm, T. Meriluoto, J. (1991). Recurrent depth maxima of the hepatotoxic cyanobacterium Oscillatoria agardhii. Canadian Journal of Fisheries and Aquatic Sciences, 48(9):1629-1634.

Izaguirre, G., Jungblut, A.-D., Neilan, B. (2007). Benthic cyanobacteria (Oscillatoriaceae) that produce microcystin-LR, isolated from four reservoirs in southern California. Water Research, 41(2), 492-498.

Krienitz, L., Ballot, A., Kotut, K., Wiegand, C., Pütz, S., Metcalf, J. S., Stephan, P. (2003). Contribution of hot spring cyanobacteria to the mysterious deaths of Lesser Flamingos at Lake Bogoria, Kenya. FEMS Microbiology Ecology, 43(2), 141-148.

Kurmayer, R., Christiansen, G. (2009). The genetic basis of toxin production in cyanobacteria. Freshwater Reviews, 2(1):31-51.

M. Skulberg, O., W.Carmichael, W., A.Codd, G., RandiSkulberg. (1993). Chapter 9 Taxonomy of Toxic Cyanophyceae (Cyanobacteria). Algal Toxins in Seafood and Drinking Water.145-164

Mehrabiani, M. A., Zolfaghari, M. R., Shhhosseiny, M. H. (2016). Identification of cyanobacteria producing microcystin in amirkelaye lagoon by pcr.

Moore, C., Juan, J., Lin, Y., Gaskill, C., \& Puschner, B. (2016). Comparison of protein phosphatase inhibition assay with LC-MS/MS for diagnosis of microcystin toxicosis in veterinary cases. Mar Drugs, 14(3), 54.

Mrdjen, I., Morse, M., Ruch, R., Knobloch, T., Choudhary, S., Weghorst, C., Lee, J. (2018). Impact of Microcystin-LR on Liver Function Varies by Dose and Sex in Mice.Toxins, $10(11), 435$.

Prescott, G. W. (1982). Algae of the western Great Lakes area, with an illustrated key to the genera of desmids and freshwater diatoms: Otto Koeltz Science Publishers.

Raziuddin, S., Siegelman, H. W., Tornabene, T. (1983). Lipopolysaccharides of the 
cyanobacterium Microcystis aeruginosa. Toxins, 137(1-2), 333-336.

Schirrmeister, B. E., Sanchez-Baracaldo, P., \& Wacey, D. (2016). Cyanobacterial evolution during the Precambrian.International Journal of Astrobiology, 15(3), 187-204.

Seckbach, J. (2007). Algae and cyanobacteria in extreme environments (Vol. 11): Springer Science \& Business Media.

Seifert, M., McGregor, G., Eaglesham, G., Wickramasinghe, W., Shaw, G. (2007). First evidence for the production of cylindrospermopsin and deoxy-cylindrospermopsin by the freshwater benthic cyanobacterium, Lyngbya wollei (Farlow ex Gomont) Speziale and Dyck. Harmful algae,. 6(1), 73-80.

Smith, F. M., Wood, S. A., Van Ginkel, R., Broady, P. A., Gaw, S. J. T. (2011). First report of saxitoxin production by a species of the freshwater benthic cyanobacterium, Scytonema Agardh. Toxins, 57(4): 566-573.

Vijayakumar, R., Raja, S. S. (2018). Secondary Metabolites: Sources and Applications: BoD-Books on Demand.

Wehr, J. D. (2011). Freshwater algae: Identification and use as bioindicators. Journal of Phycology, 47(2), 436-438.

Weller, D. (2011). Detection, identification and toxigenicity of cyanobacteria in New Zealand lakes using PCR-based methods. New Zealand Journal of Marine and Freshwater Researc, 45(4), 651-664.

Wicks, R.J. and Thiel, P.G. (1990). Environmental factors affecting the production of peptide toxins in floating scums of cyanobacterium Microcystis aeruginosa in a hypertrophic African reservoir. Environmental Science Technology, 24, 1413-1418.

Wood, S., Heath, M., Kuhajek, J., \& Ryan, K. (2010). Fine-scale spatial variability in anatoxin-a and homoanatoxin-a concentrations in benthic cyanobacterial mats: implication for monitoring and management. Journal of Applied Microbiology, 109(6), 2011-2018.

York, P. V., \& Johnson, L. R. (2002). The freshwater algal flora of the British Isles: an identification guide to freshwater and terrestrial algae: Cambridge University Press. 